\title{
THE TOXEMIAS OF PREGNANCY.
}

\author{
II.-Late. \\ By DAVID FYFE ANDERSON, M.B.(Glas.), M.C.O.G.,
}

Assistant to the Regius Professor of Midwifery, University of Glasgow ; Assistant Obstetric Surgeon, Glasgore Royal Maternity and Women's Hospital; Surgeon to Out-Patients, Royal Samaritan Hospital for Women, Glasgow.

The woman who has successfully weathered the storm of the early months of pregnancy is still liable to find the uterine contents a source of danger in the later months of gestation. Pregnancy is a merciless detective and is ruthless in its exposure of hidden weakness. Thus, in a pregnant woman with an oldstanding but quiescent lesion of the kidney, symptoms of toxæmia soon appear as the result of the aggravation of the renal damage: in such a case, pregnancy is merely an incident in the course of a chronic disease, and the unfortunate woman after delivery is in a worse plight than before. Toxæmic manifestations in the early months are related to the digestive system, whereas those of the later stage cause attention to be focussed on the kidney.

In this article, acute yellow atrophy and nephritic toxæmia will not be considered, so that we may concentrate attention on the pre-eclamptic and eclamptic states, both most frequent among primigravidæ.

Let us consider first the pre-eclamptic syndrome. In such a case the toxæmia appears to be primarily due to the pregnant state, occurring as it does in a woman in whom no trace of previous damage, renal or otherwise, can be detected. The order of development of these pre-eclamptic manifestations has received much attention of late. So often the patient when first observed presents the complete clinical picture, making it impossible to determine which was the initial departure from normal. Symptoms may be conspicuous by their absence when definite signs are in evidence.

It has been pointed out by Browne (I932) and others that one of the earliest warnings of a developing toxæmia is an elevation of blood pressure. An observation such as this can be confirmed daily in the out-patient department: quite frequently a patient protests that she feels perfectly well, no abnormality beyond a raised blood pressure can be detected, yet that single departure from the normal is significant and warrants the closest supervision of the case.

Another sign which is often noticed in the absence of any other abnormality is œdema of the feet and ankles-and occasionally of wider distribution. Other causes of œdema have, of course, to be ruled out before ascribing to this development a toxæmic origin. Such patients, when admitted to the wards from the antenatal clinic, quite frequently develop in the course of a few days other pre-eclamptic phenomena such as raised blood pressure and proteinuria.

Oliguria and the detection of protein in the urine may first direct attention to the fact that all is not well with the patient. " "Proteinuria" is the more accurate definition inasmuch as both albumin and globulin are present, but in this paper we shall continue to use the term familiarised by long usage, viz.: "albuminuria".) In certain instances, hæmaturia is the only warning sign. 
Symptoms are also important. Complaint of headache, particularly in the frontal region, is frequently made. Lassitude and back-ache may be conspicuous. The patient may wonder why her morning sickness has returned. The recurrence of vomiting in the later months of pregnancy should always be regarded as a toxæmic manifestation and the precursor of more significant departures from the normal state unless suitable treatment be instituted. Toxæmia of bacteriological origin, as in pyelitis, must of course be excluded. Visual disturbances may be troublesome: these may be associated with œdema of the retina, but not with the characteristic appearances of "albuminuric retinitis". Should blindness develop, there is found to be partial or complete detachment of the retina. Epigastric pain should be looked upon as a serious pre-eclamptic symptom; and, on occasion, mental disturbance may be the only indication of the serious condition of the patient.

In the early detection of pre-eclamptic signs and symptoms lies one of the greatest opportunities of preventive medicine. It is impossible to over-stress the supreme importance of observing the first departure from normal. The patient may well be instructed to report forthwith any development such as headache, vomiting, visual disturbance or epigastric pain, but frequently these phenomena are absent in the early stages of the condition. Emphasis must be laid on the duty of the medical attendant to detect the signs, particularly elevation of blood pressure, œdema and albuminuria. Ante-natal care worthy of the name necessitates frequent estimations with the sphygmomanometer, together with periodic examination of the urine and routine inspection of the patient. The development of the complete clinical picture of pre-eclampsia need not be awaited before instituting treatment the presence of any one of these signs is ample warning for the exercise of the utmost care.

What is the inevitable result of the over-looked pre-eclamptic sign and symptom? Neglect involves multiplication and aggravation of these until the toxæmia finally becomes so marked that the unfortunate woman is precipitated into that most dreaded of all the toxæmias of pregnancy, eclampsia. Emphasis is laid on these pre-eclamptic manifestations, because it is only by the early recognition of a departure from the normal and the prompt treatmont of the patient that the probable sequel of eclampsia can be averted. In most cases of eclampsia there is ample warning over a period of time if cognisance of the various manifestations already indicated is taken; and even in the fulminating type of eclampsia, if the patient be observed sufficiently closely, some unusual feature will attract attention. Pre-eclamptic phenomena, it is satisfactory to know, as a rule disappear rapidly under simple treatment, and, should the progress of the patient not be all that is desired, steps may be taken to terminate the pregnancy. The abatement of these signs and symptoms is comparatively easily accomplished and is relatively simple when contrasted with the Herculean efforts which may be made to rescue an eclamptic patient from the jaws of untimely death without any assurance of success.

Three illustrative cases, recently under observation, may be cited.

I. A woman aged twenty-three years, pregnant for the second time, was kept under close supervision in view of the fact that, in her previous pregnancy, eclampsia had developed at the stage of seven months. She was seen one afternoon at the ante-natal clinic when eight months' pregnant, and, as on previous visits, she felt perfectly well and had no complaint. No abnormality was noted with the exception of a blood pressure of $1 \frac{164}{110} \mathrm{~mm} . \mathrm{Hg}$. 
Previous readings had not exceeded $\frac{120}{70} \mathrm{~mm} . \mathrm{Hg}$. In view of this she was sent into hospital. The same night, at II.IO p.m. she had a convulsive seizure, followed by another at II.45 p.m. The catheter specimen of urine then obtained showed albumin present to the extent of Esbach $\&$ parts per I,ooo. Spontaneous delivery of a dead child weighing $5 \mathrm{lb}$. occurred the following day at 5.35 a.m. In all, fifteen fits occurred-two intra-partum and thirteen post-partum. During the acute stage, the systolic blood pressure never exceeded I $_{54} \mathrm{~mm}$. Hg. The patient made a satisfactory recovery, the albumin in the urine dropping to a trace on the first day of the puerperium, and being absent thereafter. The blood pressure, too, was normal on dismissal.

In this instance, the type of eclampsia could justifiably be classed as "fulminating", and yet there was a solitary warning sign in the presence of an elevated blood pressure.

II. About the same time there was admitted to hospital with eclampsia of the ante-partum variety a primigravida aged seventeen years, the size of the uterus indicating pregnancy of seven months' duration. Albumin and blood were present in the urine and the blood pressure registered $\frac{160}{124} \mathrm{~mm} . \mathrm{Hg}$. There was no odema. In all, twenty-three fits occurred, and the patient died undelivered exactly twelve hours after the onset of convulsions. The history given was that, apart from scarlet fever at the age of eight years, she had always been healthy. During pregnancy she enjoyed good health, and at no time had any complaint until ro.20 p.m. on the night before admission when, in a tram-car, she developed severe epigastric pain, became sick and vomited. The first fit occurred at midnight.

One cannot tell in a case such as this how long danger signals such as elevated blood pressure and albuminuria had been present, but the only symptom occurred roo minutes before the first convulsive seizure.

III. A primigravida, aged thirty-two years, was admitted to hospital on account of intra-partum eclampsia. During pregnancy she had been perfectly well, but had noticed that for two or three weeks before term, her feet had become swollen. The urine showed albumin to the amount of Esbach I5 parts per I,000, the blood pressure was $1 \frac{190}{130} \mathrm{~mm} . \mathrm{Hg}$. and there was marked œdema of the lower extremities. A still-born child was delivered with forceps, and the following day the urine was clear while the systolic blood pressure was $120 \mathrm{~mm} . \mathrm{Hg}$.

The syndrome in this instance comprised œdema, albuminuria and elevation of blood pressure, but we do not know which was the initial symptom or sign. At any rate, cedema of the feet and legs for two or three weeks constituted ample warning, calling for the most careful observation of the patient.

Abnormalities such as elevation of blood pressure, œdema, oliguria and albuminuria direct attention very forcibly to the renal apparatus. The factor or factors which maintain blood pressure at normal level are still imperfectly understood, consequently it is impossible to explain why the blood pressure should become raised in the pre-eclamptic state. In the first case cited, for example, elevation of blood pressure, followed in a few hours by the appearance of albumin in quantity in the urine and by its equally rapid disappearance after delivery, would suggest the sudden action of a very powerful toxin on the renal epithelium and its abrupt withdrawal consequent upon the birth of the child. On the other 
hand, the slow liberation of toxin may have become suddenly accelerated, leading to the same result. The adjustment maintained between the maternal and foetal organisms appears to be so delicate that very little suffices to upset the equilibrium. Nothing is more dramatic in the pre-eclamptic or eclamptic subject than the rapid fall in blood pressure and disappearance of albumin from the urine very shortly after delivery.

Opportunity for post-mortem examination of the pre-eclamptic patient seldom presents itself, but, unfortunately, there is no such handicap in the case of eclampsia. Until recent years, attention has been directed more to the liver lesion than to the kidney damage. Baird and Shaw Dunn (1933) in a recent series of autopsies in eclamptic cases found it readily apparent in all instances that the hepatic lesions were of a very acute character, the changes being such as could easily have occurred within twenty-four hours. These observers have emphasized the importance of the renal factor in eclampsia, stating that the common lesion in the kidneys in fatal eclampsia is glomerular and characterized by thickening of capillary walls and of endothelium, leading to some degree of obstruction to blood-flow. Tubular changes they found to be less constant. They concluded that a degree of this renal lesion probably constitutes the anatomical basis of the albuminuria of pregnancy. It is important to note that the severity of the convulsions in eclampsia does not appear to bear any relationship to the degree of the renal change.

The significance of the renal lesion becomes more marked when one reflectso on the high incidence of recurrence of toxæmia in succeeding pregnancies showno by the woman who has been the victim of pre-eclampsia or eclampsia. Thus Young (I932) found a recurrence rate of 55.8 per cent. in a series of such cases, while Evans (1933) in a follow-up of 76 albuminuric patients discovered aftereffects in two thirds. Other investigations of this nature have yielded similar results. Women who have suffered from pre-eclampsia or eclampsia make an apparently perfect recovery, blood pressure returns to normal, albuminuria and other symptoms disappear, yet in a subsequent gestation toxæmic manifestations once more develop.

Experimental evidence has been brought forward by Browne and Dodds (I930) to show that chronic renal damage may exist during the intervals between pregnancies and yet give no clinical indication of its presence. In these cases, the subjects of occult nephritis, albuminuria appears towards the end of pregnancy. The observations of these workers suggest that in the so-called "recurrent toxæmias of pregnancy" there is all the while a mild degree of chronic renal damage which undergoes exacerbation with the strain of pregnancy, and that the "low reserve kidney" may be in the same category.

Furthermore, clinical evidence would suggest that successive normal pregnancies are not always without baneful effect. Not infrequently one encounters such a case in which a woman has passed through three or four pregnancies without the least upset, and has emerged apparently scathless, only to develop raised blood pressure, albuminuria, edema, etc., in the fourth or fifth gestation. Such findings direct attention once more to the renal apparatus: they suggest that a slight degree of renal damage has been caused by three or four apparently normal pregnancies, and that the fourth or fifth, as the case may be, has proved to be the limit of tolerance, with the result that the renal damage becomes manifest through the development of toxæmic signs and symptoms. It would seem that a 
woman cannot have an indefinite number of pregnancies without suffering the consequences, and that for many the normal limit is four, as referred to in the previous paper.

No exact knowledge regarding the incidence of eclampsia can be obtained, and that mainly for three reasons.

I. Convulsions and eclampsia are not synonymous terms. Patients may exhibit toxæmic signs and symptoms without convulsions and a fatal issue may result. Should a post-mortem examination be carried out, the finding of the characteristic renal and hepatic lesions points definitely to the existence of eclampsia. In the event of permission for autopsy being refused; an accurate diagnosis cannot be made. For example, a woman who had passed through several pregnancies uneventfully, was admitted to hospital with toxæmic manifestations, and a particularly marked elevation of blood pressure. One day she fell back dead without warning. At the postmortem examination she was found to have a ruptured aorta and pronounced atheroma of the entire vessel. This catastrophe might have happened at any time apart from pregnancy, but the raised blood pressure incidental to her toxæmia undoubtedly hastened its occurrence. However, in addition, there were characteristic eclamptic lesions in liver and kidneys, although convulsions had never occurred.

II. The occurrence of convulsions during pregnancy does not necessarily indicate eclampsia. Too frequently the discovery of pregnancy in convulsive states is automatically followed by the diagnosis of eclampsia when more accurate investigation would point to other causes such as epilepsy, hysteria, meningitis, etc. Two illustrative cases may be mentioned.

A woman, who was reported to have had several fits, was sent to a general hospital in an unconscious condition. There she was discovered to be pregnant and was thereupon transferred to the Royal Maternity Hospital as a case of eclampsia. The information elicited from the relatives was that the patient had passed through five pregnancies uneventfully, and that she had had no illness of note. For ten weeks she had complained of headache and earache, and the previous evening began to vomit. At 6 a.m. on the day of admission she was found unconscious.

Examination revealed pregnancy at the stage of six months: there was neither œdema nor albuminuria, and the blood pressure registered $\frac{122}{74} \mathrm{~mm}$. Hg. On lumbar puncture, the cerebro-spinal fluid was seen to be turbid and under tension: bacteriological examination showed a heavy pneumococcal infection, and the diagnosis of pneumococcal meningitis was made. The patient died in a little over four hours after admission.

Similar features were noted in another case sent to hospital as post-partum eclampsia. Diagnostic lumbar puncture showed that the patient suffered from meningitis of the meningococcal type. She died ten minutes after admission.

III. Eclampsia is not a notifiable disease, and therefore, while one can acquire accurate data as to the fatalities for which it is responsible, one cannot obtain reliable information as to the numbers developing this toxæmia who recover.

Doubtless most cases of eclarnpsia are concentrated in hospital, in urban areas. at least. 
TABLE I. Cases of eclampsia admitted to the Glasgow Royal Maternity and Women's Hospital $\underset{\infty}{\mathrm{\infty}}$ during the years 1926-33 inclusive (574 in all).

\begin{tabular}{|c|c|c|c|c|c|c|c|c|c|c|c|c|c|}
\hline Year & Total & Jan. & Feb. & March & April & May & June & July & Aug. & Sept. & Oct. & Nov. & Dec \\
\hline 1926 & 69 & 2 & 5 & 9 & 3 & 5 & 8 & 10 & 4 & 13 & 5 & 1 & 4 \\
\hline 1927 & 86 & 7 & 4 & 5 & 9 & 3 & 6 & 9 & 10 & 11 & 5 & 7 & 10 \\
\hline 1928 & 74 & 6 & 7 & 8 & 5 & 6 & 6 & 9 & 4 & 7 & 8 & 3 & 5 \\
\hline 1929 & 93 & 10 & 10 & 7 & 10 & 9 & 4 & 4 & 13 & 9 & 9 & 4 & 4 \\
\hline 1930 & 59 & 1 & 3 & 3 & 10 & 5 & 2 & 7 & 8 & 6 & 4 & 10 & - \\
\hline 1931 & 54 & 4 & 3 & 5 & 4 & 3 & 4 & 7 & 3 & 7 & 6 & 4 & 4 \\
\hline 1932 & 73 & 10 & 10 & 6 & 5 & 7 & 9 & 6 & 4 & 3 & 3 & 5 & 5 \\
\hline 1933 & 66 & 5 & 2 & 5 & 3 & 10 & 4 & 8 & 6 & 6 & 8 & 8 & 1 \\
\hline $\begin{array}{l}1926- \\
33 \text { incl. }\end{array}$ & 574 & 45 & 44 & 48 & 49 & 48 & 43 & 60 & 52 & 62 & 48 & 42 & 33 \\
\hline
\end{tabular}

TABLE II. Deaths occurring in Glasgow certified as due to eclampsia during the years 1926- $\$ 36$ inclusive (101 in all). Figure in brackets denotes those deaths which occurred in the Glasgowo Royal Maternity and Women's Hospital (total 68).

\begin{tabular}{|c|c|c|c|c|c|c|c|c|c|c|c|c|c|}
\hline Year & Total & Jan. & Feb. & March & April & May & June & July & Aug. & Sept. & Oct. & Nov. & Dec. \\
\hline 1926 & $\begin{array}{ll}11 & (7)\end{array}$ & - & 2 & $2(2)$ & - & 1 & 1 (1) & $2(2)$ & - & 2 (2) & - & - & 1 \\
\hline 1927 & 9 (7) & 2 (1) & 1 (1) & - & - & - & 1 (1) & 1 & - & - & - & 1 (1) & $3(3$ \\
\hline 1928 & $15(10)$ & 1 & $1(1)$ & 1 (1) & 3 (2) & - & 1 (1) & 3 (2) & 2 (1) & $1(1)$ & 1 & 1 (1) & - \\
\hline 1929 & $5 \quad(4)$ & 1 (1) & - & 1 (1) & - & - & - & - & 1 & - & 1 (1) & - & $1(1)$ \\
\hline 1930 & $16(9)$ & 2 (1) & - & 3 (1) & 2 & 1 (1) & 1 (1) & $1(1)$ & 2 (1) & - & - & 3 (3) & 1 \\
\hline 1931 & $14(8)$ & - & 1 & 2 & - & - & $2(1)$ & - & 4 (2) & 3 (3) & - & 2 (2) & - \\
\hline 1932 & $19(13)$ & 1 & 1 (1) & 2 (1) & - & - & $3(1)$ & 2 (1) & 3 (3) & 1 (1) & 2 (2) & $2(2)$ & $2(1)$ \\
\hline 1933 & $12(10)$ & 3 (2) & - & - & 1 (1) & 4 (3) & 1 (1) & - & 1 (1) & 1 (1) & - & 1 (1) & - \\
\hline $\begin{array}{l}1926-33 \\
\text { inclusive }\end{array}$ & $101(68)$ & $10(5)$ & 6 (3) & $\begin{array}{ll}11 & (6)\end{array}$ & 6 (3) & 6 (4) & $10(7)$ & 9 (6) & $13(8)$ & 8 (8) & 4 (3) & $10(10)$ & $8(5$ \\
\hline
\end{tabular}

Of the deaths in Glasgow certified as due to eclampsia, 67.3 per cent. occurred in the RoyaP Maternity and Women's Hospital. Over this period of 8 years, of 574 cases of eclampsia? admitted, 68 died, the hospital death-rate for eclampsia being, therefore, 11.8 per cent. 
Graph showing, during the years 1926-33 inclusive

(a) Variation according to months of 574 cases of eclampsia admitted to the Glasgow Royal Maternity and Women's Hospital

(b) Maternal deaths from eclampsia in Glasgow

(c) Maternal deaths from eclampsia in the Royal Maternity and Women's Hospital

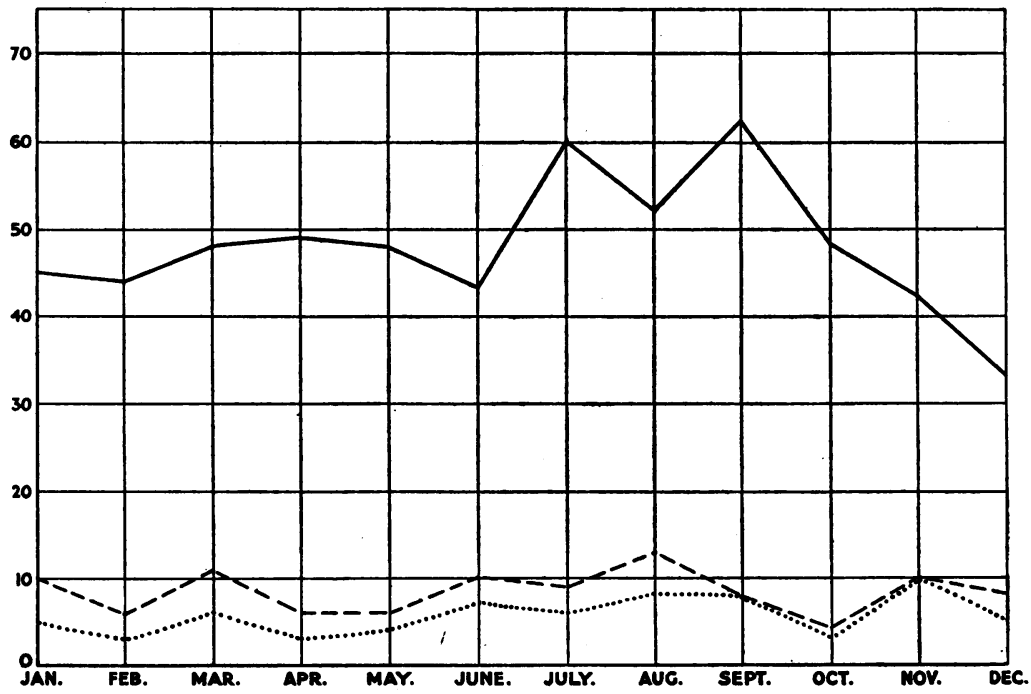

Table I. shows the number treated in the Glasgow Royal Maternity and Women's Hospital during the years I926-33 inclusive. 'The deaths from eclampsia in Glasgow during the same period are shown in Table II. The numbers vary in different months and from year to year, but from the graph it appears that, over the period indicated, the maximal incidence of eclampsia is in the months of July and September. Such an observation is not in accordance with the statement often made that eclamptic attacks are more frequent in cold and rainy weather and rare in warm, dry weather.

Földes (r933) attempts to show that the pathogenesis of eclampsia is essentially the same as, and represents a special case of the pathogenesis attributed to epilepsy, and, in his view, the conception and term of toxæmia of pregnancy should be abandoned. In both conditions he considers that there is a general disturbance in the metabolism of water and minerals and a local predisposition in the brain, with the result that fluid accumulates in the tissues and spaces enclosed by the capsules of the brain, leading to increased pressure in these tissues and spaces and hence to irritation of the cortical centres. Atmospheric conditions have an influence on the frequency of epileptic attacks, and they are mentioned by him as being among the factors which may cause such disturbances of the water and mineral metabolism as may lead to eclampsia. "The causal connections," he proceeds, " may be understood by considering that a sudden drop of the barometric pressure associated with rainy weather leads to retentions, and that, in warm and dry weather, there is an increased perspiration which prevents retentions."

All sorts of investigations have been conducted in an effort to determine the cause of eclampsia. Particular attention has been centred on the blood. From 
personal observations, it would appear that such variations in its constituents as may be shown are not present in all cases, and, at any rate, are accompaniments of the condition, not being primarily ætiological. Only one or two of the more constant and striking changes will be mentioned.

The inorganic sulphate of the blood has been found to be raised considerably above the normal level in eclampsia (Anderson and Tompsett, I932), although little variation has been noted in the non-protein nitrogen. Various authors have shown that, in cases of nephritis and cardio-renal disease, there is an increased retention of inorganic sulphate coincident with the increased retention of non-protein nitrogen, inorganic sulphate being retained in proportionately greater amount than nitrogen. Once more, the kidney is brought prominently before one in connection with eclampsia. Probably the finding of blood nonprotein nitrogen within physiological limits in eclampsia can be explained by the sudden action, of relatively short duration, of some toxin on the renal epithelium. It is possible that, relative to nitrogen, inorganic sulphate is a more difficult substance to excrete, and that, therefore, its retention may be an earlier indication of renal impairment than is afforded by the study of the non-protein nitrogen or urea content.

One of the most constant and noteworthy changes in the blood in both preeclampsia and eclampsia is the subnormal calcium value. Taking $9 \mathrm{mgm}$. per IOO c.c. as the lower limit of normality, 82 per cent. of a series of 44 cases of eclampsia showed subnormal values (Anderson, 1932). Calcium deficiency is probably not due to an absence of calcium from the body, but to the incapacity to utilise the calcium which is present. The lowering of the serum calcium level is not peculiar to eclampsia, but relative to pre-eclamptic and other toxæmic? conditions, the proportion of cases showing a low value is much greater.

Following on this observation, and in view of the fact that calcium ions are believed to play an important part in allaying the irritability of the tissues in which they are contained, it was decided to estimate the calcium content of the cerebrospinal fluid in the hope that variations in concentration might throw some light on the occurrence of convulsions. However, this hypothesis was not substantiated: there was no abnormal variation in the level of the cerebro-spinal fluid calcium in eclampsia which could be connected with the onset of convulsive seizures.

The constancy of the cerebrospinal fluid calcium in association with variable diminutions in the calcium content of the serum is noteworthy as indicating that the diminution in the serum calcium level in toxæmic cases is due to a reduction in the non-diffusible calcium (Anderson, I933).

Anselmino, Hoffmann and Kennedy (I932) have carried out an important investigation, as a result of which they advance the hypothesis that "toxic albuminuria" of pregnancy and eclampsia are endocrine disturbances, probably of a pluriglandular nature, but in which great over-production of the hormones of the posterior pituitary dominates the picture. Not only do they state that they have been able to detect an increased content of posterior pituitary hormones in the blood of all their cases, but they have found it possible to demonstrate a relationship between the amount present and the severity of the symptoms. It is interesting to note that, by the injection of pituitrin experimentally, there have been produced many of the features of eclampsia, including diminution of blood calcium. There 
is added interest in the observation that the effect of the posterior pituitary has been found to be lessened by certain narcotics and hypnotics which happen to be the same drugs employed quite empirically in the Stroganoff treatment of eclampsia (I930).

During the early months of pregnancy the anterior lobe of the pituitary exhibits increased activity, as shown by the Zondek-Aschheim test, and this probably inhibits posterior lobe activity. Later on faulty balance may permit the activity of the posterior lobe to manifest itself at an earlier stage and to a greater extent than normal. Thus toxic albuminuria of pregnancy may be the result of hormonal imbalance due to premature and excessive activity of the posterior lobe of the pituitary. The development of eclampsia may coincide with some sudden and still more pronounced increase in posterior lobe secretion or with the superimposition of some additional factor. For some time the conception that abnormal endocrine activity must be responsible for the development of the later toxæmias of pregnancy has been gaining ground. Now that it has received confirmation through the work of Anselmino, Hoffmann and Kennedy, it is hoped that an efficient antidote (perhaps in the form of a potent anterior lobe preparation) may be found to counteract the excessive activity of the posterior lobe.

Meanwhile, there is no specific for the treatment of eclampsia. It is a common experience that many recover with the ordinary routine treatment, while others succumb in spite of this and more energetic measures.

As in pneumonia, the nursing is of the greatest importance. In view of the deficiency of calcium in the blood, we have treated eclamptics by the injection of calcium gluconate, mainly intramuscularly and intravenously, the usual dose being Io c.c. of a Io per cent. solution. Some patients after injection had no further fits, and this happy result was ascribed to the calcium administered. In others, however, one fit followed another in rapid succession, and a fatal result ensued. We have, therefore, abandoned the routine administration of calcium gluconate because, from the cases observed, it was clear that a single injection of Io c.c. of a Io per cent. solution was not sufficient to cause the immediate cessation of fits even if given intravenously. Caution, too, is necessary in repeating the dose, especially if given by the intravenous route. Our experience is that conservative treatment, in which attention to elimination and the judicious administration of sedatives figure prominently, gives the best results. More radical procedures should be reserved for such cases as make an unsatisfactory response.

How should the pre-eclamptic be treated? Rest in bed is essential; proper evacuation of the bowels must be secured; the skin and kidneys must be encouraged to act. The diet, while restricted, must not be too severely curtailed. We have found that the patient who is condemned to non-nourishing fluids exclusively develops a high degree of ketosis. A sufficiency of carbohydrate at least ought to be ensured. Nourishing drinks are useful. Milk may be given with advantage: not only does it provide protein, but it conveys to the body supplies of calcium and other mineral elements of which there is a deficiency in the maternal blood in many instances. As there is no noteworthy increase in the blood urea or nonprotein nitrogen in pre-eclamptic toxæmia, such easily assimilable protein is of advantage in preventing or ameliorating cedema. The administration of thyroid extract often proves beneficial. 
In the early detection and prompt treatment of pre-eclamptic manifestations, as has already been stressed, preventive medicine has one of its greatest opportunities, but the treatment of eclampsia is still empirical and the results problematical at the best. In the pre-eclamptic state, quite simple treatment quickly yields beneficial results: if not, the pregnancy can be terminated before the patient's condition becomes critical. Prophylaxis it is impossible to overemphasize, because, in the present state of our knowledge, it is only by the exercise of really adequate ante-natal supervision that eclampsia can be prevented and a considerable decrease in maternal mortality thereby secured. The astounding results in the clinics in which the patients receive very complete ante-natal supervision justify the claim that eclampsia is, save in a few instances, a preventable disease.

I am indebted to Professor J. M. Munro Kerr for the facilities afforded me at the Royal Maternity and Women's Hospital, and to Dr. John Walker, of Glasgow Public Health Department, for supplying information concerning deaths from eclampsia.

REFERENCES.

Anderson, D. F., (1932), Brit. Jour. Exper. Path., 13, 182.

Idem (1933), Ibid. 14, 155.

Idem and Tompsett, S. L., (1932) Tbid. 13, 130.

Baird, D. and Dunn, J. S., (1933), Jour. Path. and Bact. 37. 291.

Browne, F J., (1932), Brit. Med. Jour., I. 320.

Idem and Dodds, G. H., (1930), Jour. Obstet. and Gyn. of Brit. Emp., 37, 476.

Evans, M. D. A., (1933), Ibid. 40, 1024.

Földes, E., (1933). A New Approach to Dietetic Therapy. (Boston. R. G. Badger. The Gorham Press).

stroganoff, W., (1930). The Improved Prophylactic Method in the Treatment of Eclampsia. (E. \& 8 . Livingstone, Edinburgh).

Young, J., (1932), Jour. Obstet. and Gyn. of Brit. Emp., 39, 310.

\title{
STAMMERING.
}

\author{
By W. KINGDON WARD.
}

Hon, Therapist to the Speech Department, West End Hospital for Nervous Diseases, etc.

In dealing with the question of the inception of stammering we have to consider three main elements; the neurological, the psychological, and the habit factors.

The last is, of course, present in all cases. So, in the majority of cases, are both the first and the second, although in varying degrees. There are, however, certain stammers into which the psychological factor does not enter in any degree which necessitates its being specially dealt with; and others in which it is paramount, while the neurological element is negligible, and the habit factor enters more with reference to a habitual mental attitude than to the speech as such.

A classification of stammering is not easy; but it is necessary to recognise the existence of distinct types. A certain amount of failure to deal with this disorder is undoubtedly attributable to the attempt on the one hand to refer all stammering to one common type of origin, and on the other to see, in the wide variation in phenomenal disturbance connected with stammering, a correspondingly wide field of variation in type of this disorder.

The latter of these polar mistakes seems to be more or less dying out, if it has not already done so, and the former to have been substituted for it-doubtless on 